\title{
VALIDAÇÃO DE MÉTODO ESPECTROFOTOMÉTRICO NA REGIÃO DO UV PARA QUANTIFICAÇÃO DE FAMOTIDINA EM CÁPSULAS
}

\author{
Lívia Botacini Favoretto, Juliana Maria Oliveira Souza, Rudy Bonfilio*, Roberta de Cássia Pimentel Azevedo e Magali \\ Benjamim de Araújo \\ Departamento de Farmácia, Universidade Federal de Alfenas, Rua Gabriel Monteiro da Silva, 700, 37130-000 Alfenas - MG, Brasil
}

Recebido em 21/10/09; aceito em 22/3/10; publicado na web em 18/6/10

\begin{abstract}
VALIDATION OF AN UV SPECTROPHOTOMETRIC METHOD FOR QUANTIFICATION OF FAMOTIDINE IN CAPSULES. This work describes the validation of a method for quantification of famotidine in capsules by UV spectrophotometry using as solvents buffer solution at $\mathrm{pH} 2.5$ and buffer solution at $\mathrm{pH}$ 4.5. The results show that the method is practical, selective, accurate, precise and linear from 10.0 to $25.0 \mu \mathrm{g} / \mathrm{mL}$ of famotidine in both solvents. However, a variance analysis showed a lower mean percentage of famotidine when buffer at $\mathrm{pH} 2.5$ is used. This effect was attributed to the instability of famotidine in acidic media. Therefore, the use of $\mathrm{pH} 4.5$ buffer was considered suitable for analysis of famotidine in capsules.
\end{abstract}

Keywords: famotidine; validation; UV spectrophotometry.

\section{INTRODUÇÃO}

A famotidina (Figura 1) é um antagonista competitivo do receptor $\mathrm{H}_{2}$ da histamina. Seu mecanismo de ação consiste na inibição da secreção ácida gástrica, evitando que o seu excesso possa causar dor e mal estar. Este fármaco é utilizado no tratamento de úlceras pépticas e da hiperacidez gástrica. ${ }^{1-3}$ Os bloqueadores dos receptores $\mathrm{H}_{2}$, como a famotidina, reduzem eficazmente a secreção ácida gástrica estimulada por alimentos, pentagastrina, insulina, cafeína ou histamina. Esta diminuição está relacionada com a redução tanto do conteúdo gástrico, quanto do volume do suco gástrico, e ocorre em indivíduos sadios e com úlceras pépticas. A famotidina é bem absorvida por via oral e atinge níveis terapêuticos em cerca de $1 \mathrm{~h}$. É eliminada principalmente por via renal, sendo também excretada no leite materno. ${ }^{1,4}$ São raros os efeitos indesejados e, em geral, são revertidos com a interrupção do tratamento. ${ }^{2}$ Pode ter sua ação diminuída por antiácidos e sucralfato, porém pode diminuir a ação do cetoconazol e itraconazol. Também pode sofrer ou provocar aumento das reações adversas com depressores da medula óssea. ${ }^{5}$<smiles>NC(N)=Nc1nc(CSCCC(N)=NOS(N)=O)cs1</smiles>

Figura 1. Estrutura química da famotidina

Na literatura encontram-se inúmeros trabalhos referentes à determinação de famotidina em formulações farmacêuticas. Dentre os métodos descritos estão a eletroforese capilar com detecção no UV, ${ }^{6-9}$ potenciometria, ${ }^{10}$ voltametria, ${ }^{11}$ espectrofotometria, ${ }^{12-17}$ cromatografia líquida de alta eficiência (CLAE) $)^{18-31}$ e análise por injeção em fluxo. ${ }^{32-34}$

As Farmacopeias Brasileira e Americana registram a monografia para famotidina na forma farmacêutica comprimido com quantificação por CLAE. ${ }^{35,36}$ No entanto, para identificação do fármaco é utilizada a varredura espectral com solução de tampão fosfato $\mathrm{pH}$ $2,5,{ }^{35} \mathrm{e}$, ainda, no ensaio de dissolução para comprimidos a quanti-

*e-mail: rudybonfilio@yahoo.com.br dade de fármaco liberado da forma farmacêutica é quantificada por espectrofotometria utilizando-se solução de tampão fosfato $\mathrm{pH} 4,5 .{ }^{36}$

A forma farmacêutica cápsulas contendo famotidina não se encontra inscrita, até o presente momento, em compêndios oficiais e, dentre os medicamentos manipulados em farmácias, este fármaco tem se destacado para o atendimento de pacientes com transtornos gástricos. Tendo em vista o grande número de métodos espectrofotométricos utilizados na rotina de laboratórios de controle de qualidade devido à facilidade, economia e rapidez dessa técnica, o presente trabalho teve por objetivo validar um método analítico por espectrofotometria no UV para quantificação de cápsulas de famotidina $40 \mathrm{mg}$, visando a aplicação em laboratórios de controle de qualidade de medicamentos.

\section{PARTE EXPERIMENTAL}

\section{Materiais}

Produtos farmacêuticos, padrão de referência e reagentes

Cápsulas de famotidina $40 \mathrm{mg}$ foram adquiridas de três farmácias de manipulação e codificadas como amostras A, B e C, respectivamente. A amostra A contém como excipientes amido $99 \%$ e aerosil $1 \%$. A amostra B contém os excipientes hidroxipropilmetilcelulose PA $10 \%$, aerosil $1 \%$, celulose microcristalina $20 \%$, estearato de magnésio $1 \%$ e amido (quantidade suficiente para uma cápsula). A amostra C contém os excipientes celulose microcristalina $30 \%$, aerosil $1 \%$ e amido (quantidade suficiente para uma cápsula).

A famotidina Galena (Brasil), lote FTE0280404, validade em 03/09, foi utilizada como padrão de referência, apresentando teor declarado de $99,8 \%$.

Os reagentes empregados foram grau analítico (P.A.) e adquiridos da Vetec ${ }^{\circledR}$, (Brasil): acetato de sódio tri-hidratado; ácido acético glacial; ácido clorídrico; ácido fosfórico; fosfato de potássio monobásico; hidróxido de sódio e trietilamina. Os solventes metanol e acetonitrila foram grau UV/HPLC (Vetec ${ }^{\circledR}$, Brasil).

\section{Equipamentos}

Para execução dos ensaios foram utilizados os seguintes equipamentos: espectrofotômetro UV/Vis Shimadzu ${ }^{\circledR}$ (Japão), modelo UV1601 PC; balança analítica modelo 410 (Kern ${ }^{\circledR}$, Alemanha); medidor de pH modelo PA 200 (Marconi ${ }^{\circledR}$, Brasil); banho ultrassônico modelo 
USC 2800A (Unique ${ }^{\circledR}$, Brasil); sistema de purificação de água TKA modelo LAB-UPW (Carl Zeiss Jena ${ }^{\circledR}$, Alemanha); sistema de filtração a vácuo (Millipore ${ }^{\circledR}$, Brasil) e membrana PTFE de 0,45 $\mu \mathrm{m}$ e $13 \mathrm{~mm}$ de diâmetro (Millipore ${ }^{\circledR}$, Brasil). $^{2}$

\section{Método}

\section{Espectro de absorção}

Varreduras espectrais, nas faixas de absorção entre 400 e 200 $\mathrm{nm}$, foram realizadas para identificação do pico de máxima absorção da famotidina, a partir de soluções estoque de famotidina padrão, utilizando-se como solventes soluções de tampão fosfato $\mathrm{pH} 2,5 \mathrm{e}$ 4,5 , respectivamente, nas concentrações finais de $25 \mu \mathrm{g} / \mathrm{mL}$.

\section{Validação do método analítico}

A validação do método analítico foi realizada de acordo com especificações da literatura, ${ }^{37}$ da RE n ${ }^{0} 899$ de 29/5/2003 ${ }^{38}$ e do ICH. ${ }^{39}$

\section{Linearidade}

Para construção da curva analítica, preparou-se solução do padrão, na concentração de $250 \mu \mathrm{g} / \mathrm{mL}$, dissolvendo-se a famotidina em soluções de tampão fosfato $\mathrm{pH} 2,5$ e 4,5, respectivamente. Alíquotas de 1,$0 ; 1,3 ; 1,8 ; 2,2$ e 2,5 mL foram transferidas para balões volumétricos de $25 \mathrm{~mL}$, obtendo-se soluções com concentrações de 10,0; 13,$0 ; 18,0 ; 22,0$ e $25,0 \mu \mathrm{g} / \mathrm{mL}$. Foram preparadas 5 réplicas de cada concentração, para cada condição de $\mathrm{pH}$, procedendo-se às leituras das soluções em espectrofotômetro a $265 \mathrm{~nm}$. A curva analítica foi construída correlacionando-se os valores médios das absorvâncias em função da concentração.

\section{Seletividade}

Foram preparadas soluções do padrão, da forma farmacêutica cápsulas (amostras A, B e C) e dos excipientes (amostras A, B e C) nas concentrações finais de $18,0 \mu \mathrm{g} / \mathrm{mL}$ de famotidina, utilizandose soluções de tampão fosfato $\mathrm{pH}$ 2,5 e 4,5, respectivamente, como solventes. Foram realizadas varreduras espectrais $(400-200 \mathrm{~nm})$ do padrão, das amostras e dos excipientes.

\section{Precisão}

A precisão do método foi avaliada aos níveis de repetibilidade e de precisão intermediária. Na repetibilidade prepararam-se 12 réplicas das soluções de famotidina padrão para cada $\mathrm{pH}$ das soluções de tampão fosfato $(2,5$ e 4,5) nas concentrações finais de $18,0 \mu \mathrm{g} /$ $\mathrm{mL}$. Procederam-se às leituras das soluções em espectrofotômetro a $265 \mathrm{~nm}$, registrando-se os valores das absorvâncias e efetuando-se o cálculo da estimativa do desvio padrão relativo entre as determinações. A precisão intermediária foi avaliada através da comparação entre as leituras de uma mesma concentração realizadas por analistas diferentes em dias diferentes. Foram preparadas 6 réplicas de soluções de famotidina padrão, em cada dia, utilizando-se soluções de tampão fosfato $\mathrm{pH}$ 2,5 e 4,5, respectivamente, nas concentrações finais de 18 $\mu \mathrm{g} / \mathrm{mL}$. Procederam-se às leituras das soluções em espectrofotômetro a $265 \mathrm{~nm}$, registrando-se os valores das absorvâncias e efetuando-se o cálculo da estimativa do desvio padrão relativo das determinações.

\section{Exatidão}

A exatidão do método de análise foi determinada pelo teste de adição e recuperação, onde soluções da famotidina padrão e da forma farmacêutica cápsulas (amostras A, B e C) com concentrações finais de $250 \mu \mathrm{g} / \mathrm{mL}$ foram preparadas, utilizando-se soluções de tampão fosfato $\mathrm{pH} 2,5$ e 4,5, respectivamente. Alíquotas de $1,0 \mathrm{~mL}$ das soluções das amostras a $250 \mu \mathrm{g} / \mathrm{mL}$ foram transferidas para 9 balões volumétricos de 25,0 mL. Posteriormente, foram adicionados em triplicata 0,$3 ; 0,8$ e $1,2 \mathrm{~mL}$ da solução contendo o padrão a $250 \mu \mathrm{g} /$ $\mathrm{mL}$. Dessa forma, foram obtidos adicionados contendo amostras na concentração final de $10 \mu \mathrm{g} / \mathrm{mL}$ e padrões nas concentrações de 3,0 (23,1\% de padrão); 8,0 (44,4\% de padrão) e $12,0 \mu \mathrm{g} / \mathrm{mL}$ (54,5\% de padrão). Portanto, a exatidão foi verificada contemplando o intervalo linear do procedimento, ou seja, três concentrações: baixa, média e alta, com três réplicas cada. Os valores de recuperação, expressos em porcentagem, foram determinados a partir das respostas analíticas obtidas com os adicionados em função da quantidade teórica de padrão adicionado.

\section{Limite de detecção $(L D)$}

O limite de detecção das amostras (A, B e C), sob as condições experimentais estabelecidas, foi determinado efetuando-se 20 leituras correspondentes ao branco (soluções de tampão fosfato $\mathrm{pH}$ 2,5 e 4,5). A estimativa do limite de detecção foi determinada através da seguinte equação:

$$
\mathrm{LD}=(\mathrm{DP} \times 3) / \mathrm{IC}
$$

em que DP é o desvio padrão relativo entre as leituras do branco e IC é a inclinação da curva analítica.

\section{Limite de quantificação $(L Q)$}

O limite de quantificação das amostras (A, B e C) foi estabelecido a partir de 20 leituras do branco (soluções de tampão fosfato $\mathrm{pH} 2,5 \mathrm{e}$ 4,5). A estimativa do limite de quantificação foi determinada através da seguinte equação:

$$
\mathrm{LQ}=(\mathrm{DP} \times 10) / \mathrm{IC}
$$

em que DP é o desvio padrão relativo entre as leituras do branco e IC é a inclinação da curva analítica.

\section{Aplicação do método às amostras de cápsulas}

\section{Determinação de peso médio}

Para determinação do peso médio das cápsulas das amostras das farmácias A, B e C, respectivamente, seguiu-se o método descrito na Farmacopeia Brasileira, ${ }^{35}$ pesando-se individualmente 20 cápsulas, removendo-se o conteúdo de cada uma e pesando-as novamente. $\mathrm{O}$ peso médio foi calculado pela diferença dos valores individuais obtidos entre a cápsula cheia e a vazia.

\section{Doseamento das amostras}

A partir do peso médio das amostras A, B e C, respectivamente, foram preparadas soluções previamente filtradas, em quintuplicata de cada amostra e do padrão, em triplicata, em soluções de tampão fosfato $\mathrm{pH}$ 2,5 e 4,5, respectivamente, nas concentrações finais de $18 \mu \mathrm{g} / \mathrm{mL}$. As soluções foram analisadas por espectrofotometria. Os valores de famotidina em cada amostra foram expressos em porcentagem da quantidade declarada e foram obtidos através da divisão da média das respostas das amostras $(\mathrm{n}=5)$ pela média das respostas do padrão ( $n=3)$, multiplicado pelo valor declarado do padrão $(99,8 \%)$.

\section{Uniformidade de conteúdo das amostras}

$\mathrm{O}$ conteúdo de 10 cápsulas de cada amostra $(\mathrm{A}, \mathrm{B}$ e C) foi transferido individualmente para balões volumétricos de $100 \mathrm{~mL}$, utilizando-se soluções de tampão fosfato $\mathrm{pH}$ 2,5 e 4,5, respectivamente. Alíquotas de 2,25 mL das amostras, previamente filtradas, foram transferidas para balões volumétricos de $50 \mathrm{~mL}$, obtendo-se soluções com concentrações finais de $18 \mu \mathrm{g} / \mathrm{mL}$. Foram preparadas soluções padrão em triplicata, na concentração final de $18 \mu \mathrm{g} / \mathrm{mL}$. 
As soluções foram analisadas por espectrofotometria. Os valores de famotidina em cada cápsula foram expressos em porcentagem da quantidade declarada e foram obtidos através da divisão da resposta de cada cápsula pela média das respostas do padrão $(n=3)$, multiplicado pelo valor declarado do padrão $(99,8 \%)$.

\section{RESULTADOS E DISCUSSÃO}

Na monografia da $4^{\mathrm{a}}$ ed. da Farmacopeia Brasileira, para a forma farmacêutica comprimido, ${ }^{35}$ é descrito um ensaio para identificação de famotidina por espectrofotometria no UV, utilizando-se solução de tampão fosfato $\mathrm{pH} 2,5$ como solvente. Na monografia da $30^{\mathrm{a}}$ ed. da Farmacopeia Americana, o ensaio de dissolução com quantificação por espectrofotometria é descrito utilizando-se como solvente uma solução de tampão fosfato $\mathrm{pH} 4,5 .{ }^{36}$ Varreduras espectrais entre $400 \mathrm{e}$ $200 \mathrm{~nm}$ foram realizadas para identificação do pico de máxima absorbância da famotidina, a partir de soluções padrão, utilizando-se como solventes soluções de tampão fosfato $\mathrm{pH} 2,5$ e 4,5, respectivamente, nas concentrações finais de $25 \mu \mathrm{g} / \mathrm{mL}$, comprovando um máximo de absorção do fármaco no comprimento de onda relatado $(\lambda=265 \mathrm{~nm})$.

Foram construídas curvas analíticas para famotidina, utilizando-se como solventes soluções de tampão fosfato $\mathrm{pH}$ 2,5 e 4,5, respectivamente. Os resultados foram avaliados por meio da regressão linear, pelo método dos mínimos quadrados, em que a equação obtida, quando da utilização de solução de tampão fosfato $\mathrm{pH} 2,5$, foi y $=0,0307 x+0,0164$ e o coeficiente de correlação linear, $r$, igual a 0,9998 . Quando da utilização de solução de tampão fosfato $\mathrm{pH}$ 4,5 a equação obtida foi $y=0,0308 x+0,0109$ e seu coeficiente de correlação linear, r, igual a 0,9999 , com estimativa de desvio padrão relativo entre as determinações inferior a $2 \%$, em ambos os valores de $\mathrm{pH}$, demonstrando haver correlação linear entre as concentrações de famotidina e as absorbâncias lidas..$^{38,39}$

Os excipientes presentes nas formulações das amostras A, B e C, respectivamente, não apresentaram interferência na quantificação da famotidina, visto que não absorveram significativamente na região espectral próxima a $265 \mathrm{~nm}$, com os solventes utilizados, mostrando a seletividade do método (Figuras 2 a 7).

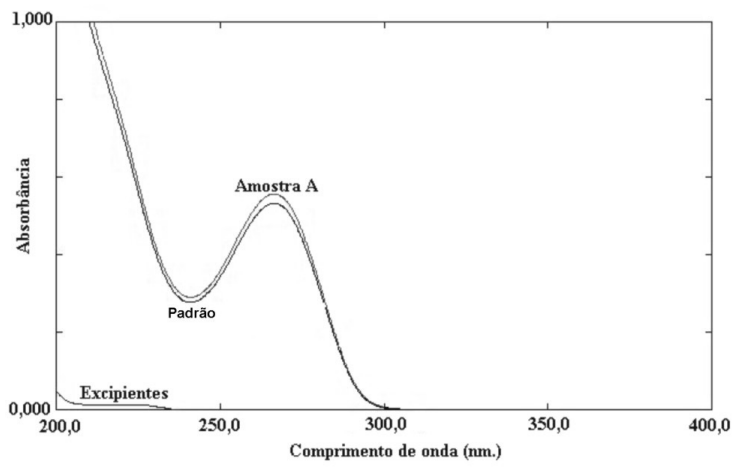

Figura 2. Varredura espectral da amostra A, excipiente A e padrão, em solução tampão fosfato pH 2,5 nas concentrações finais de $18 \mu \mathrm{g} / \mathrm{mL}$

A precisão do método, sob as condições previamente fixadas (Tabelas 1 e 2), foi determinada pela estimativa do desvio padrão relativo. Os valores médios das estimativas de desvio padrão relativo foram de $0,74 \%$ (repetibilidade) e $0,80 \%$ (intermediária) quando da utilização de solução tampão pH 2,5 como solvente e de 0,35\% (repetibilidade) e $0,43 \%$ (intermediária) quando utilizada solução tampão pH 4,5 como solvente. São aceitáveis valores de desvio padrão relativo igual ou abaixo de $5 \% .{ }^{37}$ Além disso, a precisão pôde ser confirmada nos ensaios de exatidão demonstrados nas Tabelas 1 e 2 e no ensaio de

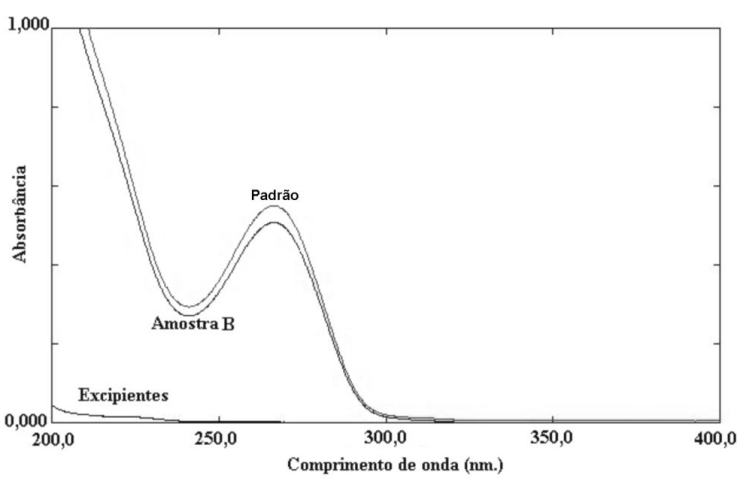

Figura 3. Varredura espectral da amostra B, excipiente B e padrão, em solução tampão fosfato $\mathrm{pH} 2,5$ nas concentrações finais de $18 \mu \mathrm{g} / \mathrm{mL}$

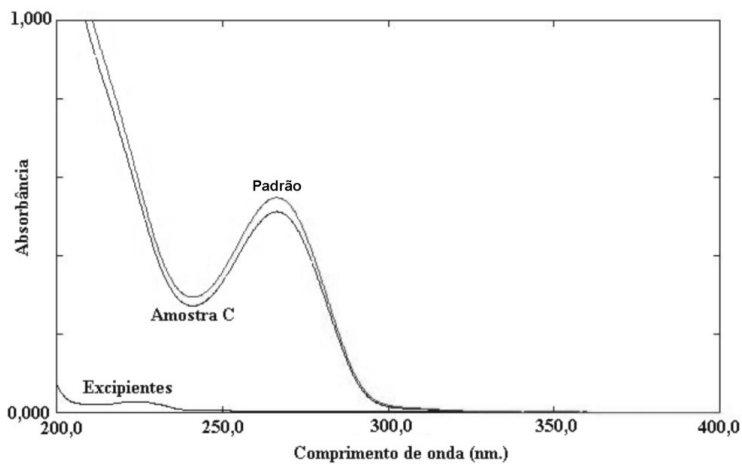

Figura 4. Varredura espectral da amostra C, excipiente C e padrão, em solução tampão fosfato $\mathrm{pH} 2,5$ nas concentrações finais de $18 \mu \mathrm{g} / \mathrm{mL}$

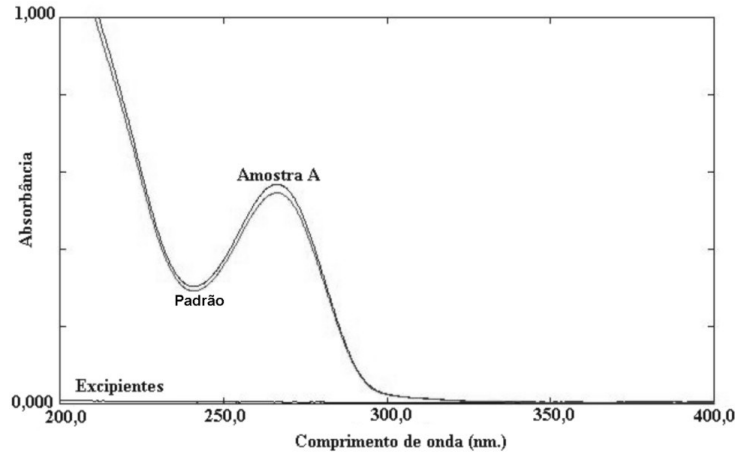

Figura 5. Varredura espectral da amostra A, excipiente A e padrão, em solução tampão fosfato $\mathrm{pH}$ 4,5 nas concentrações finais de $18 \mu \mathrm{g} / \mathrm{mL}$

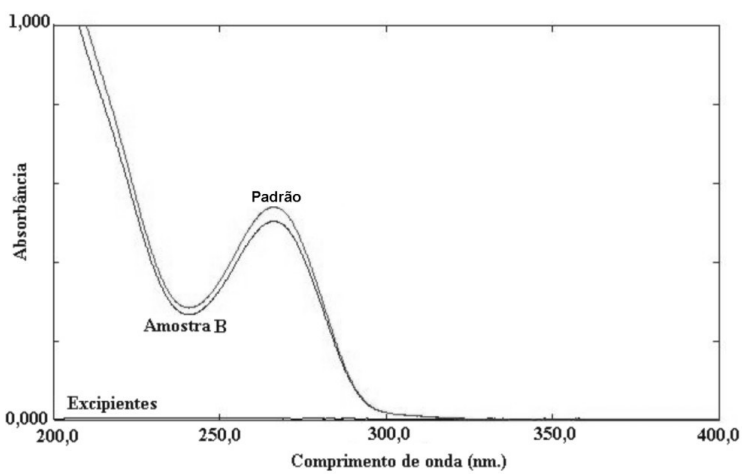

Figura 6. Varredura espectral da amostra B, excipiente B e padrão, em solução tampão fosfato $\mathrm{pH} 4,5$ nas concentrações finais de $18 \mu \mathrm{g} / \mathrm{mL}$ 


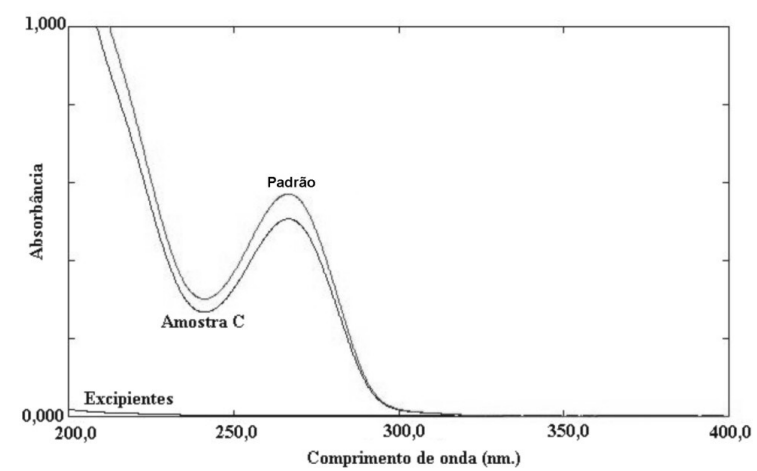

Figura 7. Varredura espectral da amostra $C$, excipiente $C$ e padrão, em solução tampão fosfato $\mathrm{pH}$ 4,5 nas concentrações finais de $18 \mu \mathrm{g} / \mathrm{mL}$

doseamento demonstrado na Tabela 3, onde as estimativas de desvio padrão relativo entre as leituras dos adicionados e das amostras foram inferiores a $5 \%$ em todos os casos.

$\mathrm{O}$ método espectrofotométrico desenvolvido demonstrou boa exatidão, que foi constatada pelo teste de recuperação. Valores médios entre 98,0 e 102,0\% para as amostras A, B e C, respectivamente, para soluções de tampão $\mathrm{pH}$ 2,5 e 4,5 indicaram exatidão adequada (Tabelas 1 e 2). ${ }^{37}$

O método demonstrou sensibilidade para os dois solventes utilizados. Os limites de detecção e de quantificação foram, respectivamente, de 0,094 e $0,314 \mu \mathrm{g} / \mathrm{mL}$ quando da utilização de solução de tampão fosfato $\mathrm{pH} 2,5$ como solvente e 0,043 e $0,145 \mu \mathrm{g} / \mathrm{mL}$ quando utilizada solução de tampão fosfato $\mathrm{pH} 4,5$. A diferença nos valores de LD e LQ para os diferentes valores de $\mathrm{pH}$ pode ser justificada por oscilações do equipamento, já que a sensibilidade é praticamente a mesma para ambos.

Os valores de teor apresentados no ensaio de doseamento das amostras A, B e C, respectivamente, atenderam aos requisitos da legislação, ${ }^{38,39}$ que estabelece limites entre 90,0 e 110, 0\% da quantidade declarada para o produto acabado (Tabela 3 ).

Foi realizado o teste de uniformidade de conteúdo das cápsulas de cada amostra (Tabela 4) e verificou-se que as amostras dos produtos A, $\mathrm{B}$ e C apresentaram valores aceitáveis, utilizando-se como solventes

Tabela 1. Resultados obtidos na determinação dos parâmetros de validação do método para famotidina, utilizando como solvente solução de tampão fosfato $\mathrm{pH} 2,5$ a $265 \mathrm{~nm}$

\begin{tabular}{|c|c|c|c|c|c|}
\hline Parâmetros & Condições & $\begin{array}{l}\text { Níveis de } \\
\text { concen- } \\
\text { tração } \\
(\mu \mathrm{g} / \mathrm{mL})\end{array}$ & $\begin{array}{l}\text { Médias } \\
\text { das absor- } \\
\text { bâncias }\end{array}$ & $\begin{array}{c}\text { DPR } \\
(\%)\end{array}$ & $\begin{array}{l}\text { Percentual } \\
\text { médio de } \\
\text { recuperação } \\
(\%)\end{array}$ \\
\hline \multirow[t]{2}{*}{ Repetitividade } & e $1^{a}$ Série & 18 & 0,540 & $1,04(n=6)$ & \\
\hline & $2^{a}$ Série & 18 & 0,541 & $0,43(n=6)$ & \\
\hline \multirow{2}{*}{$\begin{array}{l}\text { Precisão } \\
\text { intermediária }\end{array}$} & $1^{\circ}$ dia & 18 & 0,568 & $0,81(n=6)$ & \\
\hline & $2^{\circ}$ dia & 18 & 0,550 & $0,80(n=6)$ & \\
\hline \multirow[t]{9}{*}{ Exatidão } & Amostra A & 13,0 & 0,407 & $0,57(n=3)$ & \\
\hline & & 18,0 & 0,569 & $0,00(n=3)$ & 98,79 \\
\hline & & 22,0 & 0,731 & $0,16(n=3)$ & \\
\hline & Amostra B & 13,0 & 0,402 & $0,29(n=3)$ & \\
\hline & & 18,0 & 0,547 & $0,28(n=3)$ & 101,61 \\
\hline & & 22,0 & 0,697 & $0,25(n=3)$ & \\
\hline & Amostra $\mathrm{C}$ & 13,0 & 0,385 & $1,29(n=3)$ & \\
\hline & & 18,0 & 0,512 & $0,41(n=3)$ & 101,88 \\
\hline & & 22,0 & 0,655 & $0,55(n=3)$ & \\
\hline
\end{tabular}

Tabela 2. Resultados obtidos na determinação dos parâmetros de validação do método para famotidina, utilizando-se como solvente solução de tampão fosfato $\mathrm{pH} 4,5$ a $265 \mathrm{~nm}$

\begin{tabular}{lccccc}
\hline Parâmetros & Condições & $\begin{array}{c}\text { Níveis de } \\
\text { concen- } \\
\text { tração } \\
(\mu \mathrm{g} / \mathrm{mL})\end{array}$ & $\begin{array}{c}\text { Médias } \\
\text { das absor- } \\
\text { bâncias }\end{array}$ & $\begin{array}{c}\text { DPR } \\
(\%)\end{array}$ & $\begin{array}{c}\text { Percentual } \\
\text { médio de } \\
\text { recuperação } \\
(\%)\end{array}$ \\
\hline Repetibilidade & $1^{\text {a }}$ Série & 18 & 0,568 & $0,18(\mathrm{n}=6)$ & \\
& $2^{2}$ Série & 18 & 0,570 & $0,49(\mathrm{n}=6)$ & \\
Precisão & & & & & \\
intermediária & $1^{\circ}$ dia & 18 & 0,569 & $0,29(\mathrm{n}=6)$ & \\
& $2^{\circ}$ dia & 18 & 0,575 & $0,57(\mathrm{n}=6)$ & \\
Exatidão & Amostra A & 13,0 & 0,426 & $1,21(\mathrm{n}=3)$ & \\
& & 18,0 & 0,591 & $0,10(\mathrm{n}=3)$ & 100,09 \\
& & 22,0 & 0,737 & $0,41(\mathrm{n}=3)$ & \\
& Amostra B & 13,0 & 0,384 & $0,15(\mathrm{n}=3)$ & \\
& & 18,0 & 0,532 & $0,38(\mathrm{n}=3)$ & 101,84 \\
& & 22,0 & 0,685 & $0,08(\mathrm{n}=3)$ & \\
& Amostra C & 13,0 & 0,391 & $0,00(\mathrm{n}=3)$ & \\
& & 18,0 & 0,550 & $0,28(\mathrm{n}=3)$ & 98,46 \\
& & 22,0 & 0,706 & $0,08(\mathrm{n}=3)$ & \\
\hline
\end{tabular}

Tabela 3. Valores obtidos no doseamento de famotidina das amostras A, B e C, respectivamente, por espectrofotometria no UV, utilizando-se como solventes soluções de tampão fosfato pH 2,5 e 4,5 a 265 nm

\begin{tabular}{lcccccccc}
\hline & \multicolumn{2}{c}{ Padrão } & \multicolumn{2}{c}{ Amostra A } & Amostra B & \multicolumn{2}{c}{ Amostra C } \\
\hline pH do solvente & 2,5 & 4,5 & 2,5 & 4,5 & 2,5 & 4,5 & 2,5 & 4,5 \\
$\begin{array}{l}\text { Médias das absor- } \\
\text { bâncias }\end{array}$ & 0,505 & 0,540 & 0,491 & 0,545 & 0,480 & 0,537 & 0,482 & 0,544 \\
Teor(\%) & - & - & 96,99 & 100,67 & 94,82 & 99,08 & 95,26 & 100,44 \\
DPR (\%) & - & - & 1,24 & 1,63 & 1,85 & 3,22 & 3,20 & 4,37 \\
\hline
\end{tabular}

Tabela 4. Valores obtidos no teste de uniformidade de conteúdo das cápsulas (amostras A, B e C), utilizando-se como solventes soluções de tampão fosfato $\mathrm{pH} 2,5$ e 4,5

\begin{tabular}{|c|c|c|c|c|c|c|}
\hline \multirow[t]{2}{*}{ Cápsulas } & \multicolumn{2}{|c|}{ Teor amostra A (\%) } & \multicolumn{2}{|c|}{ Teor Amostra B (\%) } & \multicolumn{2}{|c|}{ Teor amostra $\mathrm{C}(\%)$} \\
\hline & $\mathrm{pH} 2,5$ & $\mathrm{pH} 4,5$ & $\mathrm{pH} 2,5$ & $\mathrm{pH} 4,5$ & $\mathrm{pH} 2,5$ & $\mathrm{pH} 4,5$ \\
\hline 1 & 95,10 & 99,01 & 94,75 & 92,50 & 98,99 & 91,73 \\
\hline 2 & 100,84 & 97,75 & 96,23 & 90,20 & 86,04 & 87,63 \\
\hline 3 & 101,40 & 99,38 & 90,70 & 90,73 & 91,96 & 88,52 \\
\hline 4 & 103,99 & 94,67 & 92,91 & 91,08 & 86,78 & 89,24 \\
\hline 5 & 103,80 & 99,01 & 92,54 & 90,55 & 88,81 & 86,56 \\
\hline 6 & 101,21 & 102,81 & 96,41 & 92,32 & 87,33 & 87,10 \\
\hline 7 & 93,81 & 97,38 & 94,20 & 90,02 & 86,78 & 89,24 \\
\hline 8 & 99,54 & 101,37 & 90,88 & 90,20 & 98,99 & 83,89 \\
\hline 9 & 95,84 & 97,75 & 92,17 & 93,91 & 93,07 & 88,70 \\
\hline 10 & 103,80 & 101,00 & 95,49 & 90,90 & 86,78 & 87,81 \\
\hline DPR $(\%)$ & 3,78 & 2,35 & 2,24 & 1,39 & 5,55 & 2,32 \\
\hline
\end{tabular}

tampão fosfato $\mathrm{pH} 2,5$ e 4,5. A uniformidade de conteúdo do produto acabado deve estar entre 85,0 e $115,0 \%$ e a estimativa de desvio padrão relativo entre as determinações deve ser inferior a $6,0 \% .{ }^{35}$

O método espectrofotométrico utilizando como solventes tampão fosfato $\mathrm{pH}$ 2,5 e 4,5 foi aplicado à forma farmacêutica cápsula das amostras A, B e C, respectivamente. Os resultados de teor de cada amostra, expressos utilizando cada solução tampão, foram comparados estatisticamente. Para análise estatística dos dados, utilizou-se esquema fatorial $3 \times 2 \times 5$ ( 3 farmácias, 2 solventes e 5 repetições). A comparação foi realizada através do teste de Tukey ao nível de 
significância de 5\%. Comparando-se as amostras de famotidina das farmácias avaliadas verificou-se que não houve diferença estatisticamente significativa ( $p>0,05)$ entre elas. Comparando-se o uso dos solventes, verificou-se que houve diferença estatisticamente significativa entre as médias percentuais de teor de famotidina, sendo que o método espectrofotométrico que utiliza tampão fosfato a $\mathrm{pH} 2,5$ apresentou médias de teores de famotidina estatisticamente inferiores aos valores resultantes da aplicação do método espectrofotométrico utilizando tampão fosfato $\mathrm{pH}$ 4,5 como solvente, segundo o teste de Tukey $(\mathrm{p}<0,05)$. Esse resultado foi atribuído à instabilidade do fármaco em condições de $\mathrm{pH}$ ácido. Relatos da literatura mostram que a estabilidade da famotidina é fortemente dependente da temperatura e do pH em solução aquosa e independente da exposição à luz, sendo que sua estabilidade máxima é verificada em $\mathrm{pHs}$ próximos a 4,0 (comparado ao $\mathrm{pH}$ próximo a 2,0$).{ }^{40}$

\section{CONCLUSÃO}

Nas condições descritas, o método espectrofotométrico para determinação quantitativa de famotidina, utilizando como solvente solução de tampão fosfato pH 2,5 e 4,5, mostrou estar de acordo com os parâmetros de validação exigidos pela legislação vigente. Apresentou resultados satisfatórios de linearidade nas faixas de 10,0 a 25,0 $\mu \mathrm{g} / \mathrm{mL}$, precisão, exatidão e seletividade. Porém, a análise estatística revelou uma menor média percentual de famotidina expressa quando o método é empregado utilizando-se o tampão $\mathrm{pH} 2,5$, em relação ao uso do tampão $\mathrm{pH}$ 4,5 como solvente. Esse resultado foi atribuído à forte instabilidade da famotidina em $\mathrm{pH}$ ácido. O método espectrofotométrico utilizando tampão $\mathrm{pH}$ 4,5 como solvente é considerado, portanto, adequado para análises de rotina do setor de controle de qualidade, visto ser de baixo custo, rápido, fácil de executar.

\section{AGRADECIMENTOS}

Ao Centro de Equivalência Farmacêutica do Núcleo Controle de Qualidade (CEFAR-NCQ/UNIFAL-MG) pelo suporte financeiro.

\section{REFERÊNCIAS}

1. Korolkovas, A.; Dicionário Terapêutico Guanabara, ed. 2006/2007, Guanabara Koogan: Rio de Janeiro, 2006.

2. Rang, H. P.; Dale, M. M.; Ritter, J. M.; Moore, P.K.; Farmacologia, $5^{\text {a }}$ ed., Guanabara Koogan: Rio de Janeiro, 2004.

3. Ikawa, J.; Tomohiko, S.; Seiichi, H.; Norifumi, M.; Susumu, T.; Biol. Pharm. Bull. 2007, 30, 1003.

4. Silva, P.; Farmacologia, 6a ed., Guanabara Koogan: Rio de Janeiro, 2002.

5. GUIA de Remédios, $5^{\mathrm{a}}$ ed., Ed. Escala Ltda: São Paulo, 2001.

6. Wu, S. M.; Ho, Y. H.; Wu, H. L.; Chen, S. H.; Ko, H. S.; Electrophoresis 2001, 22, 2717.

7. Wu, S. M.; Ho, Y. H.; Wu, H. L.; Chen, S. H.; Ko, H. S.; Electrophoresis 2001, 22, 2758.

8. Pérez-Ruiz, T.; Martínez-Lozano, C.; Tomás, V.; Bravo, E.; Galera, R.; J. Pharm. Biomed. Anal. 2002, 30, 1055.

9. Helali, N.; Tran, N. T.; Monser, L.; Taverna, M.; Talanta 2008, 74, 694.

10. Ayed, M.; Shalab, A.; Abdellatef, H. E.; Elsaid, H.; J. Pharm. Biomed. Anal. 2002, 29, 247.
11. Squella, J. A.; Rivera, C.; Lemus I.; Nunez-Vogara, L. J.; Microchim. Acta 1990, 100, 343.

12. Zuhri, A. Z. A.; Shubietah, R. M.; Badah, G. M.; J. Pharm. Biomed. Anal. 1999, 21, 459.

13. Nassr, S.; Brunet, M.; Lavoie, P.; Brazier, J.; J. Liq. Chromatogr. 2001, 24, 265.

14. Kelani, K.; Azziz, A.; Hegazy, M.; Fattah, L. A.; Spectrosc. Lett. 2002 , $35,543$.

15. Amin, A.; Shama, S.; Ahmed, I.; Gouda, E.; Anal. Lett. 2002, 35, 1851.

16. Rahman, N.; Kashif, M.; II Farmaco 2003, 58, 1045.

17. Reddy, N. R.; Prabhavathi, K.; Reddy, Y. V. B.; Chakravarthy, I. E.; Indian J. Pharm. Sci. 2006, 68, 645.

18. Suleiman, M.; Muti, H.; Abdel-Hamid, M.; Hassan, M.; El-Sayed Y.; Najib, N.; Anal. Lett. 1989, 22, 1499.

19. Maurer, H.; J. Chromatogr. 1990, 531, 369.

20. Zoest, A.; Wanwimoluk, S.; Hung, C.; J. Chromatogr., B: Anal. Technol. Biomed. Life Sci. 1991, 572, 227.

21. Kamath, B.; Shivram, K.; Newalkar B.; Shah, A.; J. Liq. Chromatogr. 1993, 16, 1007.

22. Carlucci, G.; Mazzeo, P.; Vetuschi, C.; Di Giuseppe, E.; Int. J. Pharm. 1994, 102, 271.

23. Carkir, B.; Tosun, A.; Sahin, M.; Pharm. Sci. 1997, 3, 493.

24. Zhong, L.; Yeh, K.; J. Pharm. Biomed. Anal. 1998, 16, 1051.

25. Novakovic, J.; J. Chromatogr., A 1999, 864, 193.

26. Dowling, T.; Frye, R.; J. Chromatogr., B: Anal. Technol. Biomed. Life Sci. 1999, 732, 239.

27. Chih, H.; Hsi-Min, H.; Shu-Ying, H.; Ching-Yih, S.; Ber-Lin, C.; Drug Dev. Ind. Pharm. 1999, 25, 379.

28. Campanero, M.; Bueno, I.; Arangoa, M.; Escolar, M.; Quetglas, E.; Lopez-Ocariz, A.; Azanza, J.; J. Chromatogr., B: Anal. Technol. Biomed. Life Sci. 2001, 763, 21.

29. Singh, S.; Kumar, S.; Sharda, N.; Chakraborti, A.; J. Pharm. Sci. 2002, 91, 253.

30. Zarghi, A.; Shafaati, A.; Foroutan, S. M.; Khoddam, A.; J. Pharm. Biomed. Anal. 2005, 39, 677.

31. Sultana, N.; Arayne, M. S.; Naneed, S.; Shamshad, H.; Acta Chromatogr. 2009, 21, 547.

32. Helali, N.; Adhoum, N.; Monser, L.; J. Flow Injection Anal. 2005, 22, 129.

33. Walash, M.; Sharaf-El Din, M.; Metwally, M.; Shabana, M.; Chin. Chem. Soc. 2005, 52, 71.

34. Tzanavaras, P. D.; Themelis, D. G.; Anal. Chim. Acta 2007, 588, 1.

35. Farmacopéia Brasileira, $4^{\mathrm{a}}$ ed., Atheneu: São Paulo, 1988.

36. United States Pharmacopoeia, $30^{\text {th }}$ ed., United States Pharmacopoeia Convention: Rockville, 2007.

37. Marques, M. R. C.; Brown, W.; Rev. Analytica 2002, 1, 48.

38. Brasil, Agência Nacional de Vigilância Sanitária; RE nº899 de 29 de maio de 2003. Guia para validação de métodos analíticos e bioanalíticos; Diário Oficial da União, Brasília, 02 de junho de 2003.

39. ICH Q2(R1), International Conference on Harmonization, Validation of analytical procedures: Text and methodology, 2005, http://www.ich.org/ LOB/media/MEDIA417.pdf , acessada em Fevereiro 2010.

40. Wu, Y.; Fassihi, R.; Int. J. Pharm. 2005, 290, 1. 